\title{
OPERATIVE OUTCOMES IN THORACOSCOPIC-ESOPHAGECTOMY WITH TWO-LUNG VENTILATION IN PRONE POSITION
}

\author{
Ibrahim Baloch, Bilal Umair, Asif Asghar, Muhammad Imtiaz Khan, Muhammad Shoaib Hanif \\ Combined Military Hospital/National University of Medical Sciences (NUMS) Rawalpindi Pakistan
}

\begin{abstract}
Objective: To study the post-operative outcomes of two-lung ventilation in patients undergoing prone position thoracoscopicesophagectomy.

Study Design: Prospective comparative study.

Place and Duration of Study: Department of Thoracic Surgery, Combined Military Hospital, Rawalpindi Pakistan, from Jan to Dec 2019.

Methodology: A total of 60 patients operated for both groups of thoraco-esophagectomy in which 34 patients for TLV (two-lung ventilation) and 26 patients for One-lung ventilation were studied. Patients position was prone for Two-lung ventilation in Thoracoscopic-esophagectomy. Post-op blood loss, Hospital stay, duration of anesthesia and operative morbidity was calculated.

Results: A total of 60 patients underwent two-lung ventilation in prone position out of which patient of thoracoscopicesophagectomy were 34 , while 26 underwent One-lung ventilation in semi-decubitus position thoracoscopic-esophagectomy. All of them were successfully performed without conversion to open thoracotomy. In the study with preparation span for anesthesia induction, mean time of mobilization of thoracic esophagus, mean blood loss during the thoracic mobilization phase, the mean Intensive care unit stay and total hospital stay in two-lung ventilation was less than one-lung ventilation $(p<0.05)$.

Conclusion: The present study summarized the clinical outcomes of two-lung ventilation for thoracoscopic-esophagectomy operated patients. This study data showed that Two-lung ventilation intubation in prone position is better approach during the Thoracoscopic-esophagectomy.
\end{abstract}

Keywords: Minimally invasive esophagectomy, One-lung ventilation, Thoracoscopic-esophagectomy, Two-lung ventilation.

How to Cite This Article: Baloch I, Umair B, Asghar A, Khan MI, Hanif MS. Operative Outcomes in Thoracoscopic-Esophagectomy with Two-Lung Ventilation in Prone Position. Pak Armed Forces Med J 2021; 71(5): 1820-1823. doi: https://doi.org/10.51253/pafmj.v71i5.5773

This is an Open Access article distributed under the terms of the Creative Commons Attribution License (https://creativecommons.org/licenses/by-nc/4.0/), which permits unrestricted use, distribution, and reproduction in any medium, provided the original work is properly cited.

\section{INTRODUCTON}

Esophagectomy via a Thoracoscopic and/or laparoscopic approach is very attractive because of benefits of minimally invasive surgery. ${ }^{1}$ When Cuschieri et al, Thoracoscopic Esophagectomy in the prone position first described in 1992, it has rapidly achieved popularity. ${ }^{2}$ Endeavor has continued to search for better methods of anesthesia that have increased convenience, safety and least-trauma in managing the lung during thoracic esophageal mobilization phase of Thoracoscopic-Esophagectomy. ${ }^{3}$ In 2006, Palanivelu reported thoracic mobilization of esophagus during Two-lung ventilation procedure, in prone position Thoracoscopicesophagectomy. ${ }^{4}$ After that, TLV with a single-lumen endotracheal tube has vastly achieved center of focus for many surgeon for Thoracoscopic-Esophagectomy. ${ }^{5}$

Lot of researchers have evaluated the OLV vs TLV approach of mobilization of thoracic oesophagus

Correspondence: Dr Ibrahim Baloch, Department of Thoracic Surgery, Combined Military Hospital, Rawalpindi Pakistan

Received: 30 Jul 2020; revision received: 29 Nov 2020; accepted: 22 Dec 2020 and found it satisfactory. ${ }^{6}$ Induction time for anesthesia remains lower, TLV is more technically demanding than OLV. 7 Pulmonary complications are significantly lower in the OLV groups. ${ }^{8}$ The Thoracoscopic-Esophagectomy can be performed by a single-stage laparoscopic-transhiatal approach, or by a staged thoracoscopic-laparoscopic approach. Thoracoscopic oesophageal mobilization in the lateral decubitus position is mostly done. Prone position for Thoracoscopic oesophageal mobilization has been advised as an optional to the lateral approach by Kitagawa et al, citing potential benefits such as better surgeon ergonomics and operative exposure. ${ }^{9}$ It is only the operative time that has remained a debated aspect in different studies so far. As the technical expertise has evolved, we have also endeavored to evaluate this paradigm. The goal of this study was to evaluate the use of One-lung ventilation in thoracic oesophageal surgery in terms of peri-operative outcomes of mobilization of thoracic esophagus while using two-lung ventilation in patients undergoing prone position thoracic esophagectomy. 


\section{METHODOLOGY}

This comparative prospective study was done at department of Thoracic Surgery, Combined Military Hospital Rawalpindi, from January to December 2019 after approval from the ERC/IERB (s. no: 01/08/ 19). Patients of age 35 years and more any race or sex undergoing Thoracoscopic-Esophagectomy by TLV and OLV at our hospital were considered for the study. Sample size for this study calculated by using online sample size calculator for two means. By taking Thoracic operating time $128.83 \pm 34.12$ minutes in TLV group versus $155.08 \pm 37.9$ minutes in OLV group, and at power of the test $80 \%$ and level of significance $5 \%$. Sample size was calculated using WHO sample size calculator (confidence level 95\%, power=80). Sampling technique was non-probability consecutive sampling. The calculated sample size was 30 patients in each group.

Inclusion Criteria: The patients who presented in Thoracic Surgery Department with benign esophageal disease and malignant esophageal disease stage-I to early stage-IV were included in this study.

Exclusion Criteria: Comorbidity affecting the anesthesia especially COPD patients, intrapleural adhesions requiring lung mobilization, bullous lung disease patients, patients of stage I and IV with metastasis esophageal cancer, pleural effusion, preoperative finding of invasion of mediastinal structures and patients with spinal deformities.

Informed consent was undertaken from all patients before including them in this study. The patients of TLV and OLV were selected by consecutive sampling. All surgeons are consultant thoracic surgeons having at least 3 years of post-fellowship experience. The principal investigator served as assistant in all procedure. Induction for anesthesia of the patient was done in supine position using Armored Single-lumen Endotracheal Tube (ASLET) for TLV and using Double-lumen endobronchial tube (Ethicon) for OLV. Arterial line, two wide bore peripheral venous lines were established and Foley catheter was also placed. For mobilization of thoracic esophagus all patients of TLV were then shifted to prone position and a three-port VATS approach was used. In prone position both arms were abducted about 100 degrees and elbows flexed at 90 degrees. The head fixed with a Gel Pad in order to prevent ASLET tube malposition. Using three-port VATS technique with a $10 \mathrm{~mm}$ Port placed in the fifth intercostal space on the mid-axillary line; two working 5 -mm ports placed at the 4 th and 8th intercostal space, respectively. Same likely for OLV all patients positioned to right semi-decubitus lateral position and between midaxillary and posterior-axillary line in 5th intercostal space mini thoracotomy incision given about $4-5 \mathrm{~cm}$ and collapsed right sided lung by occluding one sided of double lumen and thoracic esophagus mobilized with VATS. The anesthesia parameters during thoracoscopic were as follows Tidal volume was $350 \mathrm{ml}$ for Two-lung ventilation and $400 \mathrm{ml}$ for One-lung ventilation and changed according to fluctuation of airway pressure, Peak expiratory pressure was $5 \mathrm{cmH} 2 \mathrm{O}$; Fraction inspired oxygen was $100 \%$ and Respiratory rate was 16 time/min. Perioperative parameters recorded in two groups (Anesthesia Induction time, Thoracic esophageal mobilization time was recorded separately along with the time taken for the procedure starting from incision for ports to closure of wound, Blood loss, postoperative pulmonary complication, postop ICU and hospital stay as well post-operative morbidity and mortality was also recorded. Every patient was postoperatively observed and treated in ICU or HDU and then shifted to ward in Department of Thoracic Surgery, CMH Rawalpindi.

Data was analyzed using SPSS-21. Mean along with standard deviation calculated for numerical variable like induction time, operative time and blood loss, ICU stay and hospital stay were calculated. Chi square was applied, the $p$-value of $<0.05$ was taken as significant difference.

\section{RESULTS}

A total of 87 patients underwent ThoracoscopicEsophagectomy for esophageal cancer out of which 60 patients underwent TLV 34 patients and OLV 26 patients these fulfilled the study criteria and were recruited for the study. However there was no significant difference of (e.g. Mean age $p$-value 0.096) demographic comparison of two groups (Table-I). Age range of 35-80 years in the study with mean age of TLV 56.29 \pm 5.98 and OLV $56.35 \pm 6.07$ years. All of them underwent successful mobilization of mediastinal esophagus by VATS without requirement of conversion to open thoracotomy. Compared with TLV and OLV groups, TLV significantly better in surgical outcomes (e.g. thoracic operation time $p$-value 0.002 ) statically in (TableII), the mean preparation span for anesthesia induction was for TLV $44.00 \pm 6.005$ and OLV $68.35 \pm 8.428$ minutes. Mean time of mobilization of thoracic esophagus was for TLV $106.41 \pm 17.46$ and OLV $149.42 \pm 5.04$ minutes. Mean blood loss during the thoracic mobilization phase was for TLV $66.58 \pm 19.23$ and OLV $222.8 \pm 47.38$ 
Table-I: Characteristics of the patients.

\begin{tabular}{|c|c|c|c|}
\hline Parameters & \begin{tabular}{|c|} 
Two-lung \\
ventilation $\mathrm{n}(\%)$ \\
$34(56.7)$
\end{tabular} & \begin{tabular}{|c|} 
One-lung \\
ventilation $n(\%)$ \\
$26(43.3)$ \\
\end{tabular} & $\begin{array}{c}p- \\
\text { value }\end{array}$ \\
\hline \multicolumn{4}{|l|}{ Gender } \\
\hline Male $\mathrm{n}=47$ & $26(75.5)$ & $21(80.8)$ & \multirow{2}{*}{0.689} \\
\hline Female $n=13$ & $08(23.5)$ & $05(19.2)$ & \\
\hline Mean Age & $56.29 \pm 5.98$ & $56.35 \pm 6.07$ & 0.096 \\
\hline \multicolumn{4}{|l|}{ Smoking } \\
\hline Yes & $04(11.8)$ & $04(15.4)$ & \multirow{2}{*}{0.683} \\
\hline No & $30(88.2)$ & $22(84.6)$ & \\
\hline \multicolumn{4}{|c|}{ Tumor Histology } \\
\hline Adeno CA & $26(76.5)$ & $13(50.0)$ & \multirow{2}{*}{0.033} \\
\hline SCC & $08(23.5)$ & $13(50.0)$ & \\
\hline \multicolumn{4}{|l|}{ Tumor Site } \\
\hline Upper third & $06(17.6)$ & $08(30.8)$ & \multirow{4}{*}{0.309} \\
\hline Middle third & $08(23.5)$ & 03 (11.5) & \\
\hline Lower third & $14(41.2)$ & $13(50.0)$ & \\
\hline GEJ type 2 & $06(17.6)$ & $02(07.7)$ & \\
\hline \multicolumn{4}{|c|}{ Neoadjuvant Chemotherapy } \\
\hline Yes & $03(08.8)$ & $04(15.4)$ & \multirow{2}{*}{0.433} \\
\hline No & $31(91.2)$ & $22(84.6)$ & \\
\hline \multicolumn{4}{|l|}{ Pre T Stage } \\
\hline 2 & $08(23.5)$ & $04(15.4)$ & \multirow{3}{*}{0.726} \\
\hline 3 & $24(70.6)$ & $20(74.9)$ & \\
\hline 4 & $02(05.9)$ & $02(07.7)$ & \\
\hline
\end{tabular}

Table-II: Comparison perioperative surgical parameters between two groups.

\begin{tabular}{l|c|c|c}
\hline Parameters & $\begin{array}{c}\text { Two-lung } \\
\text { ventilation }\end{array}$ & $\begin{array}{c}\text { One-lung } \\
\text { ventilation }\end{array}$ & $\begin{array}{c}p \text { - } \\
\text { value }\end{array}$ \\
\hline $\begin{array}{l}\text { Induction time } \\
\text { (min) }\end{array}$ & $44.00 \pm 6.005$ & $68.35 \pm 8.42$ & $<0.001$ \\
\hline $\begin{array}{l}\text { Thoracic operation } \\
\text { time (min) }\end{array}$ & $106.41 \pm 17.46$ & $149.42 \pm 5.04$ & 0.002 \\
\hline Blood loss (mL) & $66.58 \pm 19.23$ & $222.81 \pm 47.38$ & 0.017 \\
\hline ICU stay (day) & $2.12 \pm 0.97$ & $3.15 \pm 0.83$ & 0.004 \\
\hline Hospital stay (day) & $7.82 \pm 1.29$ & $9.92 \pm 1.09$ & $<0.001$ \\
\hline $\begin{array}{l}\text { Respiratory } \\
\text { complication }\end{array}$ & $2.29 \pm 1.49$ & $1.73 \pm 1.19$ & 0.249 \\
\hline
\end{tabular}

ml. The mean ICU stay was for TLV $2.12 \pm 0.977$ and OLV $3.15 \pm 0.834$ days. Total hospital stay in TLV was $7.82 \pm 1.29$ and OLV $9.92 \pm 1.093$ days ThoracoscopicEsophagectomy patients. All thoracic mobilization of esophagus for esophagectomy were successfully achieved by VATS and there was no incidence of VATS conversion to Thoracotomy or any major operative complications, such as airway and pulmonary parenchymal injury, aortic or vena caval bleeding and or perioperative death. There was no incidence of major surgical complications while peri-operative pulmonary complications there is no difference (e.g. Respiratory complication $p$-value 0.249 ) between two groups (Table-III) which was managed effectively with good intensive care.
Table-III: Comparison Postoperative respiratory parameters between two groups.

\begin{tabular}{|c|c|c|c|}
\hline Parameters & $\begin{array}{c}\text { Two-lung } \\
\text { ventilation }\end{array}$ & $\begin{array}{c}\text { One-lung } \\
\text { ventilation }\end{array}$ & $\begin{array}{c}p- \\
\text { value }\end{array}$ \\
\hline $\begin{array}{l}\text { Respiratory } \\
\text { Complication }\end{array}$ & 07 (20.6) & $11(42.3)$ & \multirow[t]{2}{*}{0.249} \\
\hline Pneumonia & $03(8.8)$ & $06(23.1)$ & \\
\hline \multicolumn{4}{|c|}{ Pleural effusion } \\
\hline Bilateral & $01(2.9)$ & $04(15.4)$ & \multirow{2}{*}{ - } \\
\hline Right & $02(5.9)$ & 00 & \\
\hline \multicolumn{4}{|l|}{ Pneumothorax } \\
\hline Right & $01(2.9)$ & $01(3.8)$ & - \\
\hline
\end{tabular}

\section{DISCUSSION}

Collapse of right lung is the most essential prerequisite for thoracic esophageal mobilization in prone or semi-decubitus positioning as part of minimally invasive esophagectomy. ${ }^{10}$ The aim is that lung falls down anteriorly and thus gives a clearer view of the posterior mediastinum housing the oesophagus. This was being achieved by employing double lumen endotracheal tube which intubates the left main bronchus only allowing ventilation of left lung only and collapse of right lung. ${ }^{11}$ With the passage of time, the weaknesses of this technique have surfaced from complications of intubation for anesthesia, unsatisfactory exposure for chest operative field, difficulty to save the left recurrent laryngeal nerve injury by double-lumen endotracheal tube, the tendency of tracheal tube malposition while making a prone posture and reduced safety for re-intubation. ${ }^{12}$ Meanwhile, alternative choice for intraoperative management of tracheal intubation during Thoracoscopic esophagectomy came under lime light and a point of discussion ${ }^{13}$. Surgeons and anesthetists studying for none hazard intubation approach for adequate exposure and convenient surgical procedure. With the introduction of insufflation during VATS to decompress the ventilating lung, Two-lung ventilation technique using ASLET came out as a promising option. ${ }^{14}$ It was better outcomes in Thoracoscopic esophagectomy under Two-lung ventilation prone position. The authors found less blood loss and shorter hospital stay time in TLV group as compared to OLV group. ${ }^{15}$ Mean blood loss in that study was greater in OLV group and then in TLV. Same like Mean hospital stay. This study exhibited that Two-lung ventilation use could ease anesthesia intubation, obtain good exposure operative area and peri-operative pulmonary complications showed no mild difference between the both groups. ${ }^{16}$ Therefore, Thoracoscopic Esophagectomy in prone position followed by Two-lung ventila- 
tion could result in better peri-operative outcomes than One-lung ventilation comparative study patients.

In year of 2006, a better technique of a General anesthesia endotracheal intubation of TLV was done in 130 patients for thoracoscopic-esophagectomy in prone position, and the incidence of ARDS and pneumonia was $0.78 \%$ and $1.64 \%$, respectively. ${ }^{17}$ Recently, researchers from Japan published a result of thoracoscopicesophagectomy for 14 patients in prone position with TLV and created artificial pneumothorax by VATS, in which they reported a stable peri-operative hemodynamics and oxygenation. ${ }^{18}$

Here, we report the result of thoracoscopic-esophagectomy performed on 60 patients in prone position, with 34 patients of TLV and 26 patients of OLV. All patients underwent thoracoscopic operation without undergoing conversion to open thoracotomy or drastic complications, such as airways and thoracic parenchymal tear, aorta injury, and peri-operative mortality. Compared to OLV group, while in the TLV group had less induction time for endotracheal intubation, better during operation oxygenation status, less thoracoscopic esophagectomy time, less blood loss and postoperative hospital stay. There was no statistical difference in postoperative respiratory complications between the two groups. A major limitation of onelung ventilation surgical procedure is that it may results difficult in converting the VATS to thoracotomy. This limitation can be overcome by an endobronchial blocker tube/Fogarty catheter, and that it is plausible to affect function of left thoracic cavity if the pleura is breached during the procedure. ${ }^{19}$

\section{LIMITATION OF STUDY}

Our study has limitations, firstly it is a one hospitalbased research and might result an indeterminate patients of selection bias. Secondly, this present research is Prospective comparative study. So a well-designed randomized clinical trial (RCT) should be use in order to prevent statistical error. Thirdly, the deficiencies of prime follow-up in this research study can only be sort out with time. Thoracotomy or major complications, such as airway and pulmonary parenchymal injury, aortic bleeding, can become a major cause of perioperative mortality in patients undergoing VATS thoracic esophageal mobilization during Esophagectomy. Luckily, we did not have any such major complication or mortality.

\section{CONCLUSION}

Thoracic esophageal mobilization by employing TLV Two-lung ventilation is technically feasible and safe option in prone position while working in our setups.

Conflict of Interest: None.

\section{Authors' Contribution}

IB: Design and Analysis, BU: Data conception, AA: Data interpretation, MIK: Data interpretation, MSH: Data interpretation.

\section{REFERENCES}

1. Wang H, Feng M, Tan L. Comparison of the short-term quality of life in patients with esophageal cancer after subtotal esophagectomy via videoassisted thoracoscopic or open surgery. Dis Esop 2010; 23(5): 408-414.

2. Cuschieri A, Shimi S, Banting S. Endoscopic esophagectomy through a right thoracoscopic approach. J R Coll Surg Edinb 1992; 37(1): 7-11.

3. Smithers BM, Gotley DC, McEwan D, Martin I, Bessell J, Doyle L. Thoracoscopic mobilization of the esophagus. A 6 year experience. Surg Endosc 2001; 15(2): 176-182.

4. Palanivelu C, Prakash A, Senthilkumar R, Senthilnathan P, Parthasarathi R, Rajan PS, et al. Minimally invasive esophagec-tomy: Thoracoscopic mobilization of the esophagus and media-stinal lymphadenectomy in prone position-experience of 130 patients. J Am Coll Surg 2006; 203(1): 7-16.

5. Lin M, Shen Y, Wang H, Fang Y, Qian C, Xu S, et al. A comparison between Two-lung ventilation with $\mathrm{CO} 2$ artificial pneumothorax and Onelung ventilation during thoracic phase of minimally invasive esophagectomy. J Thorac Dis 2018; 10(3): 1912-1918.

6. Straatman J, Van Der Wielen N, Cuesta MA, Daams F, Roig Garcia J, Bonavina L, et al. Minimally invasive versus open esop-hageal resection. Ann Surg 2017; 266(2): 232-236.

7. Low DE. Open versus minimally invasive esophagectomy: what is the best approach? Frame the Issue. J Gastrointest Surg 2011; 15(9): 1497-1499.

8. Bussières JS. Open or minimally invasive esophagectomy: are the outcomes different? Curr Opin Anaesthesiol 2009; 22(1): 56-60.

9. Kitagawa H, Namikawa T, Munekage M, Fujisawa K, Munekgae E, Kobayashi M, et al. Outcomes of thoracoscopic esophagectomy in prone position with laparoscopic gastric mobilization for esophageal cancer. Langenbeck's Arch Surg 2016; 401(5): 699-705.

10. Javed A, Manipadam JM, Jain A, Kalayarasan R, Uppal R, Agarwal AK. Minimally invasive esophagectomy in prone versus lateral decubitus position: A comparative study. J Minim Access Surg 2016; 12(1): 10-15.

11. Lin M, Shen Y, Feng M, Tan L. Is two lung ventilation with artificial pneumothorax a better choice than one lung ventilation in minimally invasive esophagectomy. J Thorac Dis 2019; 11(5): 707-712.

12. Brown AM, Pucci MJ, Berger AC, Tatarian T. A standardized comparison of peri-operative complications after minimally invasive esophagectomy: Ivor Lewis versus McKeown. Surg Endosc 2018; 32(1): 204-211.

13. Zhao H, Liu G, Wei S. Short- and long-term outcomes of minimally invasive esophagectomy in elderly patients with esophageal squamous cell carcinoma. J BUON 2017; 22(6): 1540-1546

14. Zhang Z, Song Q, Lin J, Kang M. Application of mesoesophagus suspension technique in upper mediastinal lymph node dissection during thoracoscopic esophagectomy. Zhonghua Wei Chang Wai Ke Za Zhi 2016; 19(9): 999-1003.

15. Cai L, Li Y, Sun L, Yang XW, Wang W Bin, Feng F, et al. Better perioperative outcomes in Thoracoscopic-esophagectomy with two-lung ventilation in semi-prone position. J Thorac Dis 2017; 9(1): 117-122.

16. Raymond DP, Seder CW, Wright CD, Magee MJ, Kosinski AS, Cassivi $\mathrm{SD}$, et al. Predictors of major morbidity or mortality after resection for esophageal cancer: a society of thoracic surgeons general thoracic surgery database risk adjustment model. Ann Thorac Surg 2016; 102(1): 207-214.

17. Palanivelu C, Prakash A, Senthilkumar R. Minimally invasive esophagectomy: thoracoscopic mobilization of the esophagus and mediastinal lymphadenectomy in prone position-experience of 130 patients. J Am Coll Surg 2006; 203(1): 7-16.

18. Saikawa D, Okushiba S, Kawata M, Okubo T, Kitashiro S, Kawarada Y, et al. Efficacy and safety of artificial pneumothorax under two-lung ventilation in thoracoscopic esophagectomy for esophageal cancer in the prone position. Gen Thorac Cardiovasc Surg 2014; 62(3): 163-170.

19. Li Z, Liu C, Liu Y, Yao S, Xu B. Comparisons between minimally invasive and open esophagectomy for esophageal cancer with cervical anastomosis: A retrospective study. J Cardiothorac Surg 2020; 15(1): 128-132.

20. Zhang BJ, Tian HT, Li HO, Meng J. The effects of one-lung ventilation mode on lung function in elderly patients undergoing esophageal cancer surgery. Med (Baltimore) 2018; 97(1): e9500. 